\section{Nitrogen-use Efficiency Evaluation and Genome Survey of Vietnamese Rice Landraces (Oryza sativa L.)}

\author{
Nguyen Thi Thuy Hanh', Dinh Mai Thuy Linh², \\ Nguyen Quoc Trung ${ }^{1}$ and Pham Van Cuong ${ }^{3}$
}

\author{
${ }^{1}$ Faculty of Biotechnology, Vietnam National University of Agriculture, Hanoi 131000 \\ Vietnam \\ ${ }^{2}$ Center of International Plant Research Vietnam and Japan (CIPR), Hanoi 131000, \\ Vietnam \\ ${ }^{3}$ Faculty of Agronomy, Vietnam National University of Agriculture, Hanoi 131000, \\ Vietnam
}

\begin{abstract}
The overuse of fertilizers can result in many adverse effects such as decreasing fertilizer use efficiency of plants, wasting resources, increasing farming costs, and polluting our environment. Local rice landraces including indigenous and local rice varieties, may contain considerable genetic diversity that can serve as sources of germplasm for genetic improvements of nutrient use efficiency, yield, resistance to pests and pathogens, and important agronomic traits. Increasing the fertilizer use efficiency of crops by developing new rice varieties is necessary for sustainable agriculture. In this study, six rice varieties, Chiem Tay (CT), Te Tep (TT), Re Bac Ninh (RB), IR24, P6DB, and Khang Dan 18 (KD18), were evaluated for nitrogen use efficiency. Two landraces, P6DB and CT, which showed the lowest and highest values of nitrogen use efficiencies, were selected for a genome survey. Ninety-seven out of the 1051 surveyed markers indicated polymorphisms. These polymorphic markers were distributed along to each of the 12 chromosomes and were either scattered quite evenly on a chromosome or were condensed at particular regions in the physical map. The obtained information on nitrogen use efficiency (NUE) variation and the marker map should be very useful to further identify QTLs/genes involving in NUE as well as other genetic analyses toward the development of sustainable agriculture.
\end{abstract}

\section{Keywords}

Genome survey, Local rice landrace (Oryza sativa L.), Nitrogen use efficiency (NUE)

\section{Introduction}

Vietnam, as well as many other rice producing countries in Southeast Asia, consider fertilizers as one of the most important 
tools to augment crop production. Increased crop productivity has been associated with an increase in fertilizer use in general and of nitrogenous fertilizer consumption in particular. The nitrogenous fertilizer consumption in 2016 was 126-fold higher than that in 1961, while rice yield increased 3 times during the period 1961-2016 (FAO, 2016). Although the application rate of fertilizer has reduced recently, but it still remains at a high level.

The overuse of fertilizers not only results in decreases in nitrogen use efficiency (NUE) of the plants but also wastes resources and has several adverse effects on the environment and human health. Excess nitrogen $(\mathrm{N})$ fertilization of crops often leads to a reduction in net returns and groundwater contamination due to $\mathrm{NO}_{3}-\mathrm{N}$ leaching (Davies and Sylvester-Bradley, 1995; Ferguson et al., 2002; Hashimoto et al., 2007); algal blooms, as the hypoxic environments under excessive $\mathrm{N}$ can result in substantial loss of marine life and diversity (Vitousek et al., 2009); and eutrophication of terrestrial and aquatic systems (Socolow, 1999). Moreover, the overuse of $\mathrm{N}$ fertilizer is a cause of air pollution due to ammonia emissions (Misselbrook et al., 2000).

As a concept, NUE is expressed as the ratio of outputs (total plant $\mathrm{N}$, grain $\mathrm{N}$, biomass yield, and grain yield) and inputs (total $\mathrm{N}$, soil $\mathrm{N}$, or $\mathrm{N}$-fertilizer applied) (Pathak et al., 2008). Efficient use of nitrogen fertilizer in rice is low due to ammonia volatilization, denitrification, leaching, ammonium fixation, immobilization, and runoff giving further importance to the economic and ecological issues of $\mathrm{N}$ fertilization. Many studies have shown that genetic variability for NUE exists in rice (Broadbent et al., 1987; De Datta and Broadbent, 1993; TirolPadre et al., 1996; Singh et al., 1998; Inthapanya et al., 2000; Hanh et al., 2014), and therefore, there is a possibility of improving NUE in rice through genotype selection.

The rice landraces including indigenous and local varieties have been cultivated by traditional farmers, may contain considerable genetic diversity that can serve as sources of germplasm for genetic improvements of cultivated rice varieties. Vietnam is an agricultural country where rice is considered as a major food crop. Rice in this country has classified indigenous, local-traditional rice landrace and improved rice varieties in various cultivated areas across the country. In the high areas of the Red River Delta (RRD), plain upland rice is cultivated. The winter rice cultivated in northern Vietnam is characterized by high resistance to blast and tolerance to adverse ecological conditions (Ut and Kei, 2006). The rice landraces in southern Vietnam are less diverse than that of the north. The most germplasm of interest is that of the low land, deep-water rice, which is a rich gene source for disease and stress tolerance.

Given the importance of nitrogen fertilization for rice production and sustainable agriculture, developing crops that are less dependent on heavy applications of $\mathrm{N}$ fertilizers is essential for the sustainability of agriculture. Many scientific studies have focused on the NUE of crop plants and developing cultivars that can exploit nitrogen more efficiently in order to minimize losses of $\mathrm{N}$ from the soil and increase economic use of the absorbed $\mathrm{N}$. The interest in improving nutrient use efficiency has never been greater than it is now. Indeed, the traditional breeding strategies to improve NUE in crop plants have experienced a plateau, where increases in the amount of $\mathrm{N}$ used do not result in yield improvements (Chandra et al., 2012). Thus, new solutions are needed to increase yields while maintaining, or preferably decreasing, the amount of $\mathrm{N}$ used (Hawkesford, 2011).

A linkage map, also known as a genetic map, refers to the determination of the relative positions and distances between markers along chromosomes. Linkage map distances between two markers are defined as the mean number of recombination events, involving a given chromatid, in that region per meiosis cycle. The construction of detailed genetic maps with high levels of genome coverage is the first step for localizing genes or quantitative trait loci (QTL) that are associated with economically important traits, marker assisted selection, and comparative mapping between different species. This is a framework and powerful research tool for anchoring physical maps, and the basis for 
map-based cloning of genes in many species (Song et al., 2003). Advances in molecular marker technology over the past decades have led to the development of detailed molecular linkage maps of rice (McCouch et al., 1988; Harushima et al., 1998).

In Vietnam, the number of published research on NUE in rice is still limited. Nitrogen management practices have been studied to improve NUE in rice cultivars (Hung et al., 1995). The evaluation of rice yield responses and NUE under different $\mathrm{N}$-fertilizer regimes was reported (Guong et al.,1995). The effects of $\mathrm{N}$ fertilizer levels on dry matter accumulation and grain yield in an $\mathrm{F}_{1}$ hybrid rice cultivar (BoiTapSonThanh), an improved cultivar (Khangdan 18), and a local cultivar (KhauSuu) were studied by Cuong et al. (2010). However, no research has been conducted to evaluate NUE and develop crops that can exploit $\mathrm{N}$ more efficiently by using molecular methods and potential indigenous rice cultivars.

The objectives of the present study are to (1) evaluate the NUE among popular grown rice landraces in the North of Vietnam; and (2) survey the genome of the rice landraces that show the lowest and highest NUE among those studied to supply information for constructing a genetic map. The obtained results will be used for further studies on mapping QTLs for NUE. This knowledge might be useful for national breeders in improving the NUE of rice cultivars and improving the sustainability of agriculture.

\section{Materials and Methods}

\section{Rice materials}

The experiments were conducted using six rice landraces cultivated from different regions of Northern Vietnam: Chiem Tay (CT); Te Tep (TT); Re Bac Ninh (RB); IR24, which contains a resistance gene to blight disease; Khang Dan 18 (KD18), the improved cultivar grown in many provinces in Red River Delta; and P6DB, the extremely early maturing rice variety. The seeds were supplied by the Center of International Plant Research Vietnam and Japan (CIPR), Vietnam National University of Agriculture (VNUA). The growth durations during the spring season of these varieties were 90 days (P6DB), 110 days (IR24 and KD18), and 140 days (TT, CT, and RB) (PRC, 2016).

\section{Pot experiment}

A pot experiment was conducted in a net house at VNUA, under natural temperature and sunlight conditions, and with a completely randomized design. This experiment was carried out from January to June 2017.

The seeds of rice landrace were used in this study were soaked in distilled water in the dark at $30^{\circ} \mathrm{C}$ for 1 day and then imbibed in distilled water at $35^{\circ} \mathrm{C}$ for 2 days. The germinated seeds were sown in seeding trays. Twenty days after sowing, the seedlings of each rice landrace were then transplanted individually into plastic pots (23-cm diameter, 20-cm height) supplemented with approximately $5 \mathrm{~kg}$ of soil. The total $\mathrm{N}$ in the soil was measured before the pot experiment following the methods of Kjeldhal (1883).

A single plant was grown in each pot from seedling to maturity. Each genotype was cultivated 27 times: 3 nitrogen $(\mathrm{N})$ treatments per 3 harvest stages per 3 repetitions. Therefore, the entire experiment amounted to a total of 162 pots. Three nitrogen treatments, normal $(\mathrm{NN})$, low $(\mathrm{LN})$, and zero $(\mathrm{ZN})$, were applied. The NN treatment corresponded to $1,043 \mathrm{mg}$ of $\mathrm{N}$ fertilizer in the form of urea $(480 \mathrm{mg} \mathrm{N}$ per pot), which is the normal recommended level for rice $\left(120 \mathrm{~kg} \mathrm{ha}^{-1}\right)$. The $\mathrm{LN}$ treatment corresponded to $260.87 \mathrm{mg}$ of urea per pot $(120 \mathrm{mg} \mathrm{N})$, i.e., one-fourth of the normal level $\left(30 \mathrm{~kg} \mathrm{ha}^{-1}\right)$. No $\mathrm{N}$ fertilization was applied to the $\mathrm{ZN}$ treatments. Correspondence with the rates in $\mathrm{kg} \mathrm{ha}^{-1}$ in the above calculations was based on the surface area of the pots. Nitrogen fertilizer was applied in four split doses: $30 \%$ as basal, $40 \%$ at tillering, $20 \%$ at panicle initiation, and $10 \%$ at heading. Other major nutrients, phosphorus $(\mathrm{P})$ and potassium $(\mathrm{K})$, were applied to all the pots at a rate of $90 \mathrm{~kg} \mathrm{ha}^{-1} . \mathrm{P}$ was applied as a base dressing in the form of superphosphate at the rate of $2,181 \mathrm{mg}(360 \mathrm{mg} \mathrm{P})$ per pot. $\mathrm{K}$ was applied in the form of potassium chloride at the rate of $600 \mathrm{mg}(360 \mathrm{mg} \mathrm{K})$. The plants were watered every day, maintaining $4 \mathrm{~cm}$ of water above the soil level in each pot. 


\section{Sampling and measurement of traits}

Sampling was conducted 3 times throughout the entire growth period on each landrace at the following stages: active tillering (30 days after transplanting), heading (2-3 days before flowering), and harvesting.

For each sampling, three representative plants of each landrace were collected. The plant samples were separated into four parts: leaf blades, sheaths plus stems, roots, and panicles. The dry weight of the leaf blades (DWB), dry weight of the sheaths plus stems (DWS), dry weight of the roots (DWR), and total dry weight (DW) were recorded. The dry weights were determined after oven drying at $60^{\circ} \mathrm{C}$ for 7 days (until a constant weight was reached). The total dry weight of each plant corresponded to the sum of the dry weights of all 4 parts.

The NUE were calculated according to the following formula:

NUE $=\left[\right.$ Total dry weight $\left.\left(\mathrm{g} \mathrm{plant}^{-1}\right)\right] /[$ Total $\mathrm{N}$ applied (g)]

The total applied $\mathrm{N}$ was the sum of native $\mathrm{N}$ in the soil and $\mathrm{N}$ application through fertilization across three $\mathrm{N}$ applications during three growing stages.

The obtained NUE values were the basis to select the landraces that showed the lowest and highest values for generating an $\mathrm{F}_{2}$ population and for further study.

\section{Genome survey}

\section{DNA extraction}

Genomic DNA was extracted from young, fresh leaves of the two cultivars that showed the lowest and highest NUE value using potassium acetate-SDS, as described by Dellaporta et al. (1983) with minor modifications.

\section{Markers}

A total of 1051 markers (Table 1), including 656 SSRs selected from the marker set published by McCouch et al. (2002), and 395 STSs (sequence-tagged sites) designed by the Center of International Plant Research Vietnam and Japan of VNUA, were used for the whole genome survey.

\section{Polymerase Chain Reaction (PCR)}

PCR was carried out with a total solution volume of $10 \mu \mathrm{L}$, containing $1 \mu \mathrm{L}$ of each primer solution (for a total of $2 \mu \mathrm{L}$ for the forward and reverse primers) at a concentration of $10 \mu \mathrm{mol} \mathrm{L} \mathrm{L}^{-1}, 5 \mu \mathrm{L}$ of $2 \mathrm{X}$ GoTaq ${ }^{\circledR}$ Green Master Mix, $1 \mu \mathrm{L}$ of the DNA template, and 2 $\mu \mathrm{L}$ of nuclease-free water. PCR amplification was performed in a thermal cycler $(\mathrm{ABI})$ at $95^{\circ} \mathrm{C}$ for $5 \mathrm{~min}$ for $1 \mathrm{cycle} ; 94^{\circ} \mathrm{C}$ for $30 \mathrm{~s}, 53^{\circ} \mathrm{C}$ to $55^{\circ} \mathrm{C}$ for $30 \mathrm{~s}$, and $72^{\circ} \mathrm{C}$ for 30 s for 35 cycles; and $72^{\circ} \mathrm{C}$ for $7 \mathrm{~min}$ for 1 cycle. The PCR products ranged from $100-400 \mathrm{bp}$, and were from all over the 12 chromosomes.

Electrophoresis and polymorphism detection

The PCR products $(8 \mu \mu)$ were electrophoresed on $4 \%(\mathrm{w} / \mathrm{v})$ agarose gels with added ethidium bromide in $1 \times \mathrm{TAE}$ buffer at $250 \mathrm{~V}$ for $40-50 \mathrm{~min}$. depending on the size difference between amplified DNA fragments of the SSR alleles. The results were observed under a UV transilluminator.

The electrophoresis results were then scored based on the segregation patterns of the two landraces at each marker. Polymorphisms and the luminosity of bands and relative markers were scored following the marking scheme shown in Table 2. The markers that were scored with a rating of 6 or 7 were considered as polymorphic markers.

\section{Physical map construction}

A physical map was constructed based on the actual location of markers on the 12 rice chromosomes. Determining the location of the markers along each of the 12 chromosomes was completed using BLAST in two steps: (1) a markers' sequence was copied and pasted into BLAST http://www.shigen.nig.ac.jp/rice/oryzabase/ blast/search), and (2) the relative position was selected based on the chromosome location, identities (100\%), and score. A physical map in the order of the markers was then constructed in MS PowerPoint (2010). The map distance between markers was expressed in mega bases (Mb). 
Nitrogen-use Efficiency Evaluation and Genome Survey of Vietnamese Rice Landraces (Oryza sativa L.)

Table 1. Number of markers on each chromosome used for PCR

\begin{tabular}{cccccccccccccc}
\hline Chr. & 1 & 2 & 3 & 4 & 5 & 6 & 7 & 8 & 9 & 10 & 11 & 12 & Total \\
\hline No. markers & 132 & 127 & 60 & 47 & 64 & 183 & 65 & 65 & 45 & 63 & 88 & 112 & 1051 \\
\hline
\end{tabular}

Table 2. Segregation scoring system to identify polymorphisms

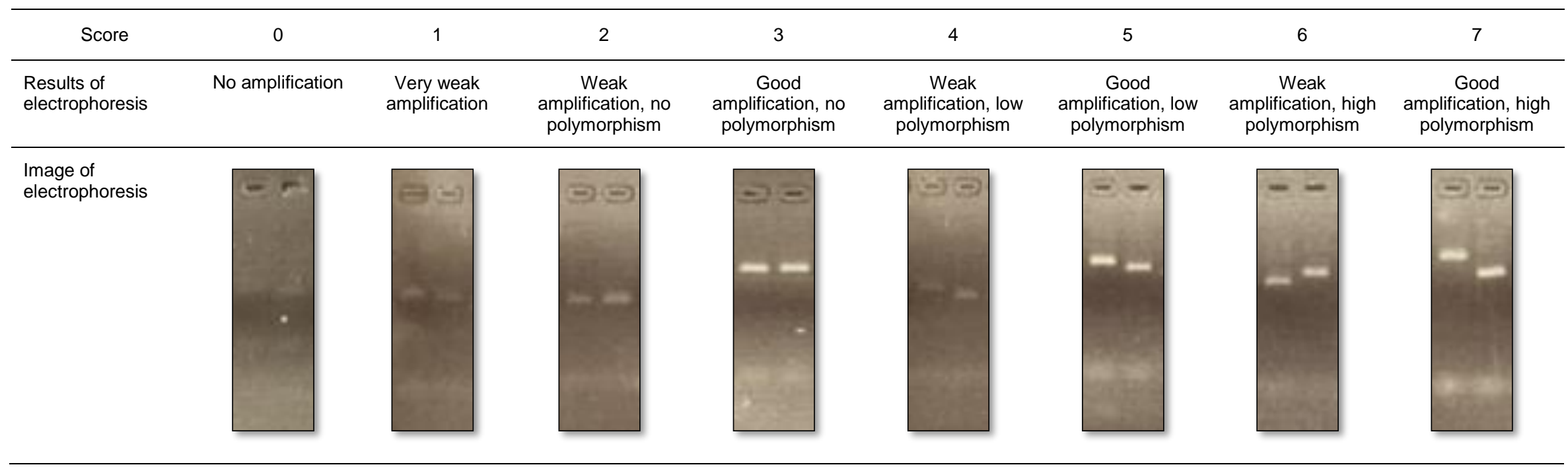




\section{Statistical analysis}

Data analyses were performed using IRRISTAT 5.0. The ANOVA procedure was used to evaluate all of the analyzed data.

\section{Results and Discussion}

\section{Dry weights following the 3 sampling stages}

The total dry weight of each plant of each landrace following each $\mathrm{N}$ fertilization treatment corresponded to the sum of the dry weights of all three parts (tillering stage) or four parts (heading and maturing stages). The total dry weight values of each rice landrace shown in Figure 1 are the average of three representative plants. The total dry weight values varied among the studied landraces. The total dry weight of each cultivar increased gradually from tillering to heading to the maturing stage, and from zero to low to normal $\mathrm{N}$ applications. The $\mathrm{CT}$ landrace showed significantly higher values than other landraces and P6DB had lower values than the other landraces under all three $\mathrm{N}$ fertilization treatments at all three growth stages (Figure 1 A-C; Figure 2 A-C).
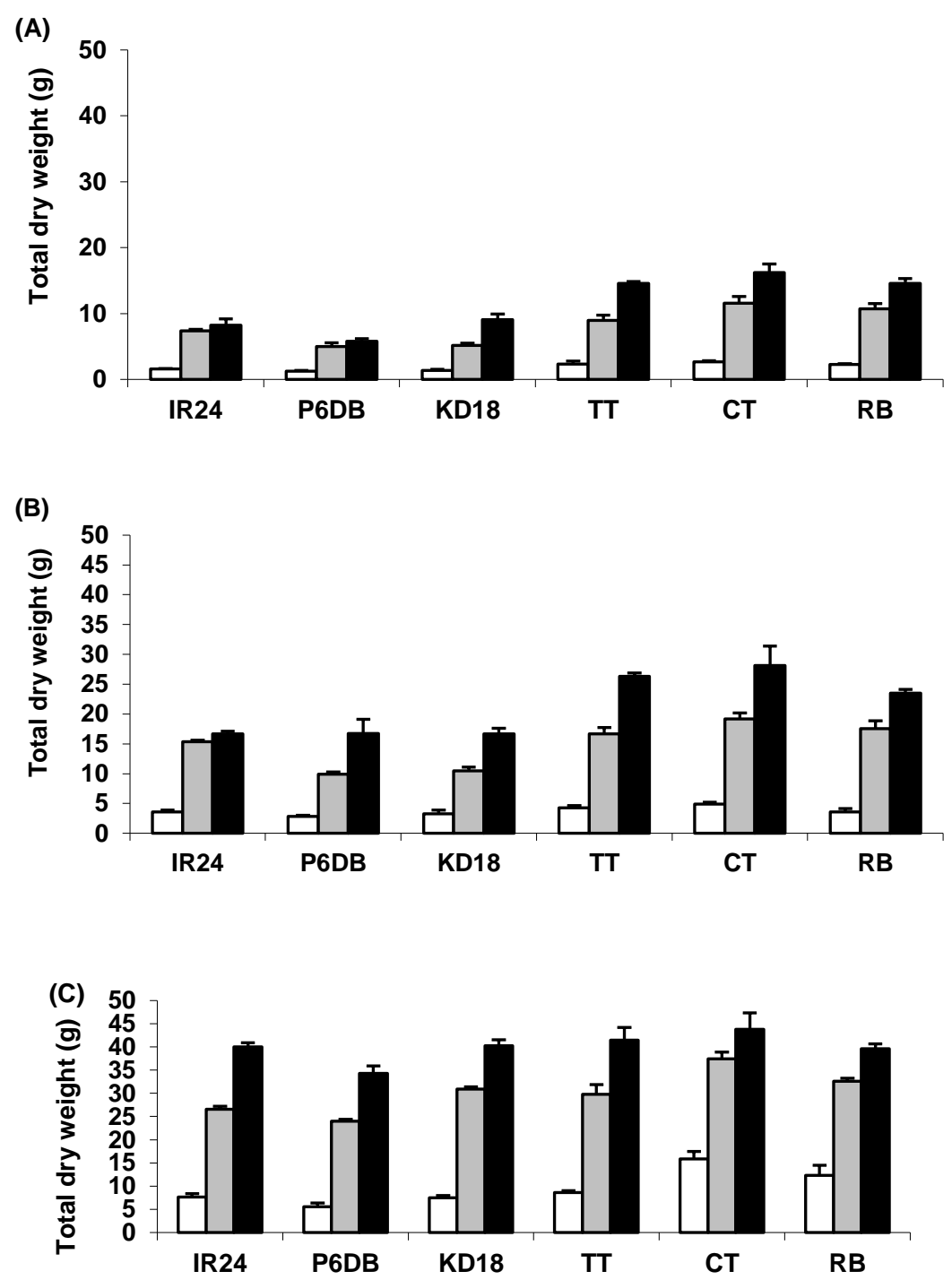

Note: Six rice landraces IR24, P6DB, Khang Dan 18, Te Tep (TT), Chiem Tay (CT), and Re Bac Ninh (RB).

Figure 1. Total dry weights of six rice landraces during the growth stages of tillering ( $\square$ ), heading $(\square)$, and maturing ( $\square)$ under three $\mathrm{N}$ fertilizer treatments of zero $(\mathrm{A})$, low $(\mathrm{B})$, and normal $(\mathrm{C})$ 

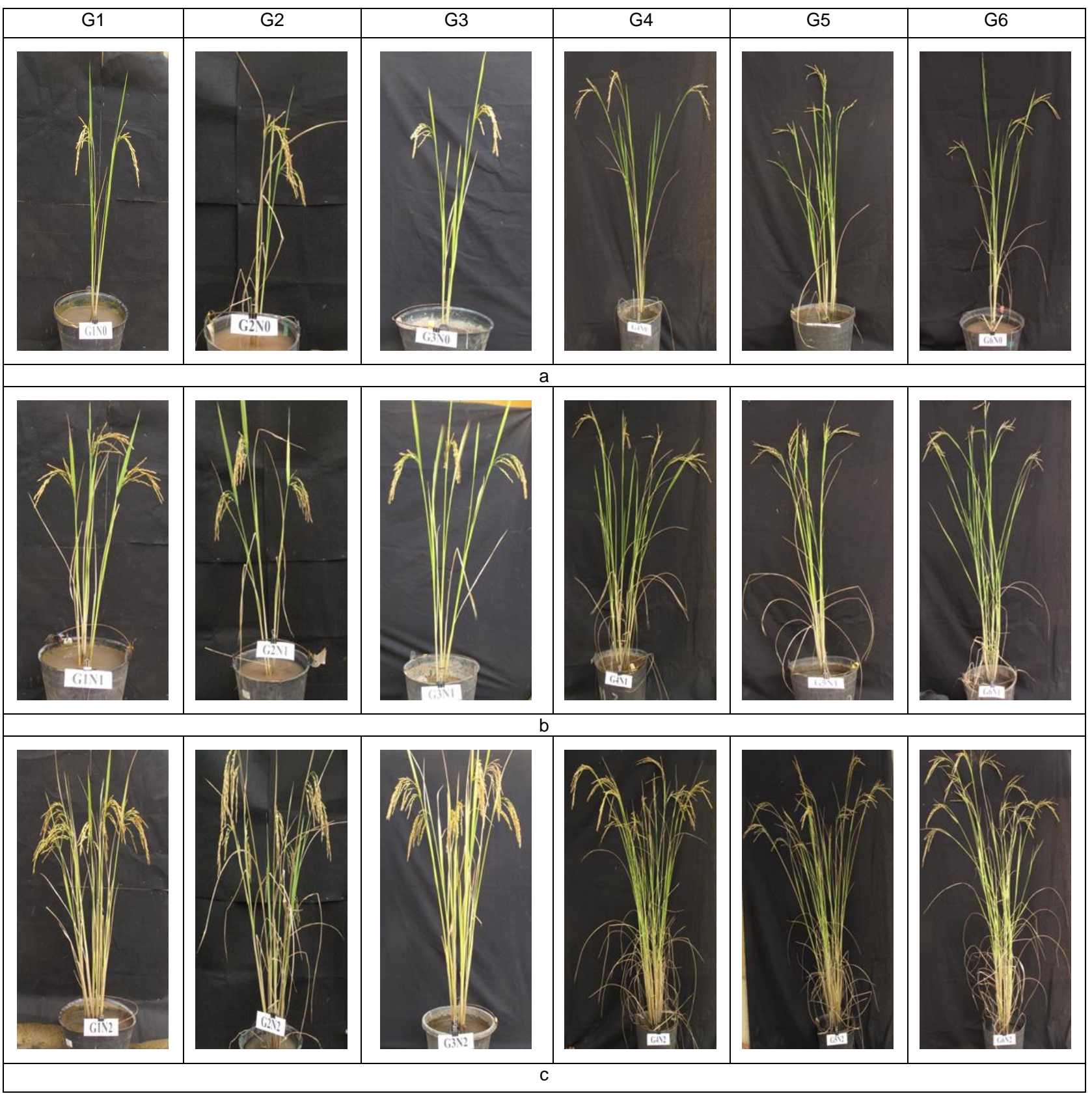

Note: Six rice landraces: G1-IR24, G2-P6DB, G3-Khang dan 18, G4-Te Tep, G5-Chiem Tay, and G6-Re Bac Ninh.

Figure 2. Phenotypes of the six rice landraces at the mature stage under the three $N$ fertilizers of zero $(A)$, low (B), and normal (C)

These results are in agreement with the results from previous studies. Many authors have confirmed significant variations in dry weight accumulation in different rice genotypes under different $\mathrm{N}$ fertilizer levels (Amano et al., 1993; Tirol-Padre et al., 1996; Singh et al., 1998; Peng et al., 1999; Inthapanya et al., 2000; Yang et al., 2002; Hasegawa, 2003; Namai et al., 2009; Hamaoka et al., 2013). Hanh et al. (2014) found a wide variation in the agronomical and physiological traits among four different rice varieties under four $\mathrm{N}$ supplies. This information might be useful for breeders to improve rice production based on genetic considerations.

\section{Nitrogen use efficiency}

The total $\mathrm{N}$ in the soil (native $\mathrm{N}$ ) was measured before conducting the pot experiment. One hundred grams of soil contained $3.5 \mathrm{mg} \mathrm{N}$ (data not shown). Based on 
the $\mathrm{N}$ content in the soil, the three levels of $\mathrm{N}$ fertilization, and the four split doses of $\mathrm{N}$ fertilizer, the NUE values were calculated by dividing the total dry weight by the available $\mathrm{N}$ (native and fertilizer) (Supplemetary Table 1). The trends in the NUE values were the same in all six cultivars: the NUE of each cultivar increased during the growth stages through tillering to heading to maturing under all three $\mathrm{N}$ regimes (Figure 3). Concerning the $\mathrm{N}$ applications, the lowest NUE value was always in the no $\mathrm{N}$ fertilizer treatment for all six rice landraces at the tillering stage. However, the NUE did not gain higher values in accordance with the increments of $\mathrm{N}$ applications. Most of the rice landraces showed the highest NUE values under $\mathrm{LN}$ at either the heading and maturing stages or at both these stages (Te Tep, Chiem Tay, and Re Bac Ninh had the highest NUE values at both stages).

(A)

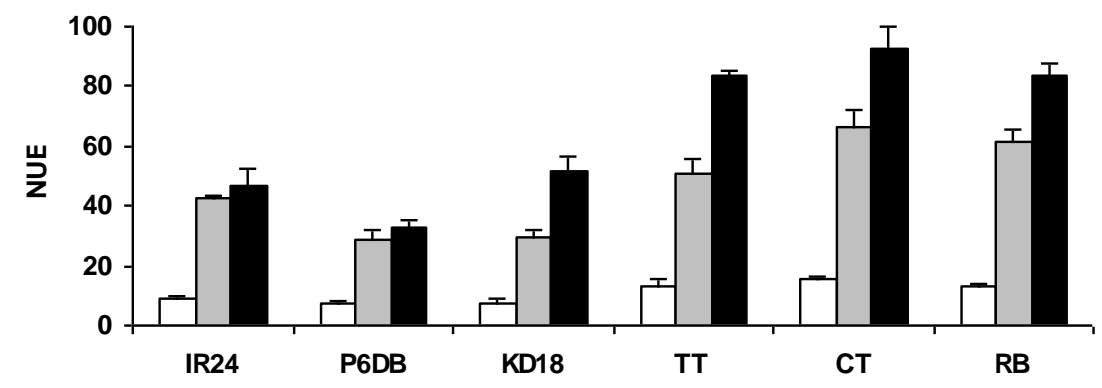

(B)

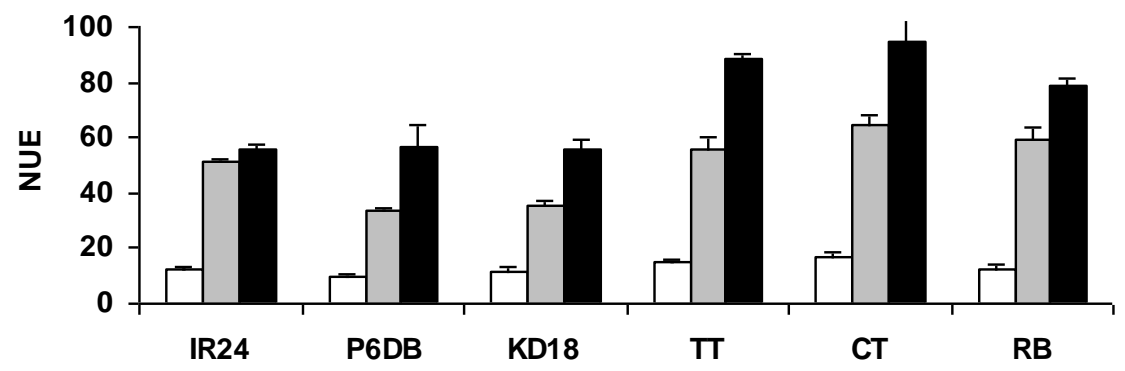

(C)

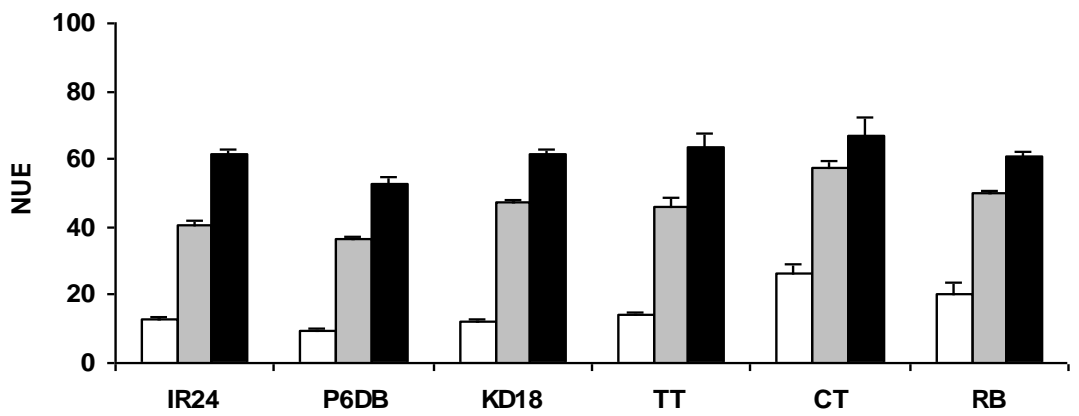

Note: Six rice landraces: IR24, P6DB, Khang Dan 18, Te Tep (TT), Chiem Tay (CT), and Re Bac Ninh (RB).

Figure 3. Nitrogen use efficiency of six rice landraces during the growth stages of tillering ( $\square$ ), heading ( $\square$ ), and maturing ( $\square$ ) under three $\mathrm{N}$ fertilizer treatments of zero $(\mathrm{A})$, low $(\mathrm{B})$, and normal $(\mathrm{C})$ 
Similar to the total dry weight values, the values of NUE varied among the studied cultivars following each $\mathrm{N}$ application. P6DB always had the lowest values across the three growth stages and $\mathrm{N}$ treatments. Interestingly, the indigenous rice landrace Chiem Tay always had the highest NUE values (Figure 3, Supplementary Table 1).

In rice, NUE has been studied by many researchers. Koutroubas and Ntanos (2003) compared NUEs among several indica and japonica cultivars. Mae et al. (2006) conducted an experiment to evaluate the NUE of the rice cultivar Akita63 and three references: Yukigesyou, Toyonishiki, and Alitakomachi. $\mathrm{Ju}$ et al. (2009) examined the NUE of recombinant inbred lines derived from a cross between two indica cultivars. Hanh et al. (2014) studied the effects of different $\mathrm{N}$ treatments on the NUEs of four rice cultivars. Although these studies were carried out by different researchers and used different rice cultivars, the results pointed out the similarity in variations in NUEs among experimental cultivars. This means that we could identify a potential higher NUE cultivar for genetic improvement as well as reduce farming costs and the negative effects of excess $\mathrm{N}$ in the environment by the present study.

From the results of this study, the lowest and highest NUE values were P6DB and Chiem Tay, respectively, and were thus selected for genome surveying and for further studies to identify QTLs/genes that relate to NUE.

\section{Polymorphism detection}

Genomic DNA was extracted from young, fresh leaves of the two selected landraces,
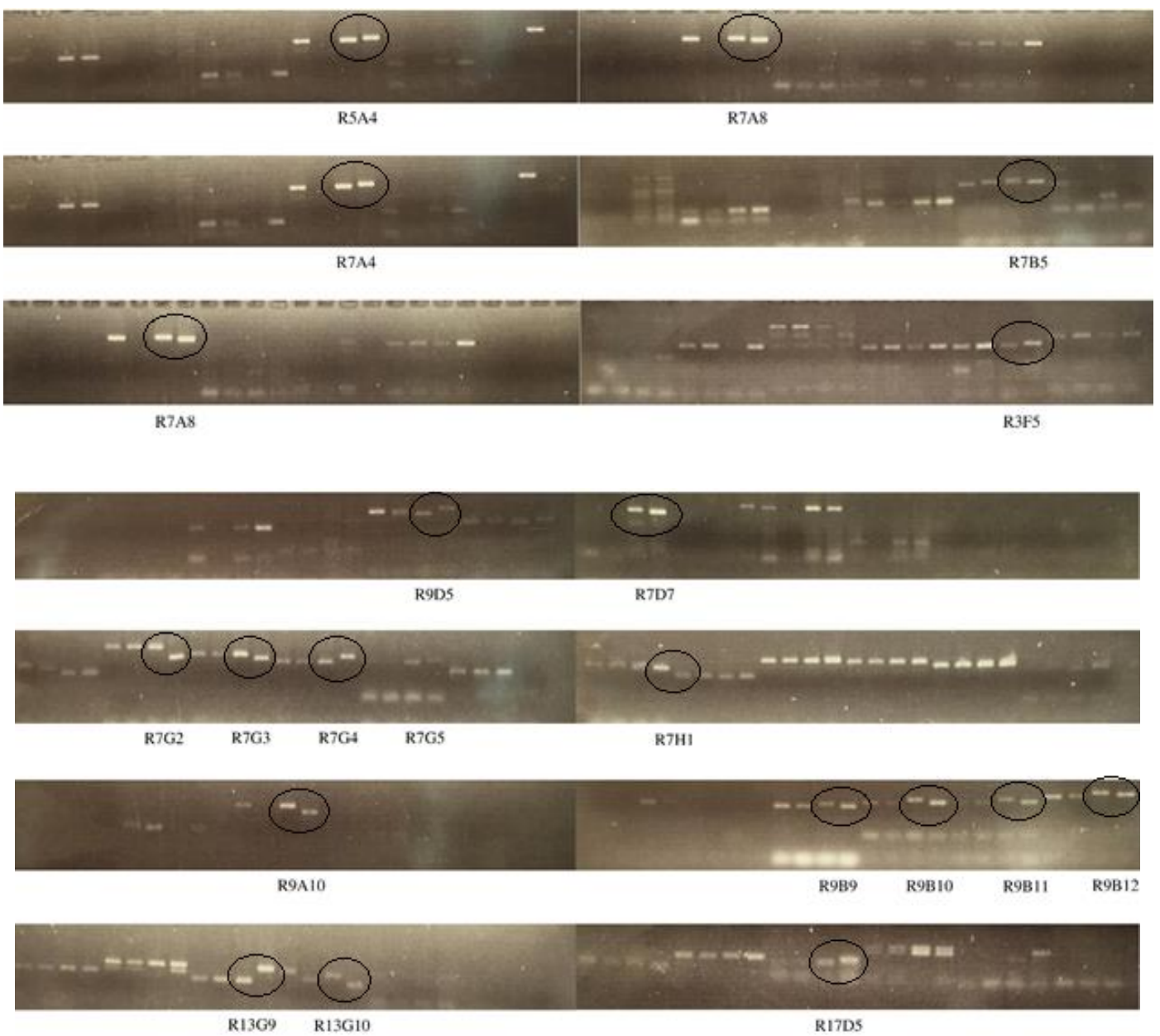

Figure 4. Screening to identify the polymorphic markers between P6DB and Chiem Tay rice landraces 
Table 3. The number of molecular markers used for the polymorphism survey

\begin{tabular}{cccc}
\hline \multirow{2}{*}{ Chromosome } & Markers surveyed & \multicolumn{2}{c}{ Markers } \\
\cline { 3 - 4 } & 132 & Polymorphic & Monomorphic \\
\hline 1 & 127 & 21 & 111 \\
3 & 60 & 6 & 121 \\
4 & 47 & 1 & 59 \\
5 & 64 & 1 & 46 \\
6 & 183 & 8 & 56 \\
7 & 65 & 21 & 162 \\
8 & 65 & 9 & 56 \\
9 & 45 & 7 & 58 \\
10 & 63 & 7 & 38 \\
11 & 88 & 4 & 59 \\
12 & 112 & 9 & 79 \\
Total & 1051 & 3 & 109 \\
\hline
\end{tabular}

P6DB and Chiem Tay. The results of gel electrophoresis (data not shown) revealed that the extractions were successful with good enough DNA quality for PCR.

A survey was conducted to identify the polymorphic markers between the two landraces, $\mathrm{P} 6 \mathrm{DB}$ and Chiem Tay. The representative gel pictures showing the polymorphism survey between the two landraces are shown in Figure 4. The polymorphism of each marker was determined based on the segregation patterns and were scored following a set marking scheme. Only markers that were scored at 6 or 7 were considered as polymorphic markers. Out of the 1051 markers tested, 97 (9.23\%) exhibited good amplified polymorphic band patterns in both landraces (Table 3). The number of polymorphic markers per chromosome ranged from 1 (on chromosomes 3 and 4) to 21 (on chromosomes 1 and 6). Overall, the polymorphic markers were evenly distributed on all 12 chromosomes, but were mainly located on chromosomes 1, 2, 5, 6, 7, 8, 9, and 11. There were a few markers on chromosomes $3,4,10$, and 12 which need to be supplemented with additional markers.

R5A4, R7A8, R7A4, R7B5, R3F5, R9D5, R7D7，R7G2，R7G3，R7G4，R7G5，R7H1,
R9A10, R9B9, R9B10, R9B11, R9B12, R13G9, R13G10, and R17D5 are representative polymorphic markers from the whole genome survey.

The rate of polymorphic markers detected in the present study is low. Similar results have also been previously reported. Septiningsih et al. (2012) reported 115 polymorphic and reliable SSR markers out of 1,074 (10.5\%). Similar results were obtained when a linkage map was constructed using a japonicaljaponica mapping population (Bing et al., 2006). Low marker polymorphism could be due to the fact that both Chiem Tay and P6DB are indica and these rice landraces might not have diverse genetic backgrounds.

\section{Physical map}

The polymorphic markers were subjected to BLAST analysis to construct the physical map. The map distance between the markers was expressed in mega bases $(\mathrm{Mb})$ and the physical map is shown in Figure 5. Chromosomes 1 and 6 both resulted in the most polymorphic markers (twenty-one markers). However, the average distance between each polymorphism on chromosome 6 was shorter than on chromosome 1 , with the distances of $1.57 \mathrm{Mb}$ and $2.25 \mathrm{Mb}$, respectively. While the polymorphic sites were 
scattered quite evenly on chromosome 1 , the polymorphic sites on chromosome 6 tended to be condensed at the position from $1 \mathrm{Mb}$ to 8 $\mathrm{Mb}$. These variations were not located near the centromere, which could be inferred that they would easily cross over in breeding.

Chromosomes 7 and 11 each had nine polymorphic sites. Since the length of chromosome 7 is longer, the average distance between the varied sites was longer than that of
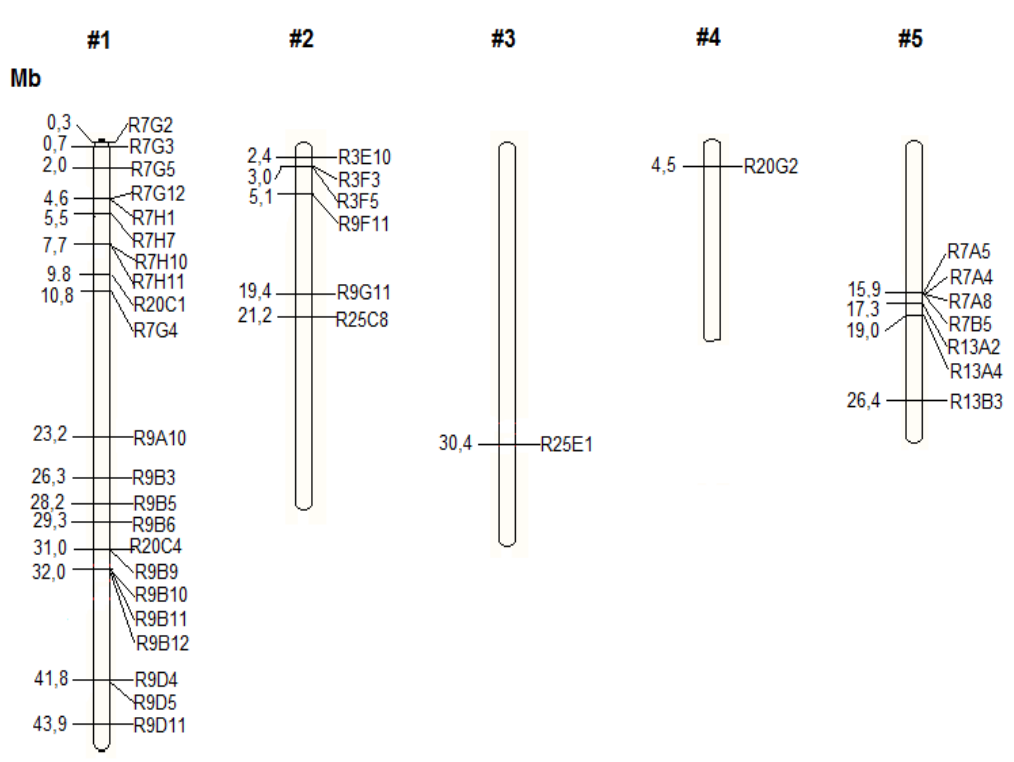

chromosome 11. These two chromosomes showed relatively similar patterns of polymorphism distribution which were far from the centromeres and more concentrated at the lower ends of each chromosome.

Chromosome 5 had eight identified polymorphic markers. The average distance between each marker was $3.91 \mathrm{Mb}$. It is noticeable that all of the polymorphism markers were concentrated at the position from $15.9 \mathrm{Mb}$
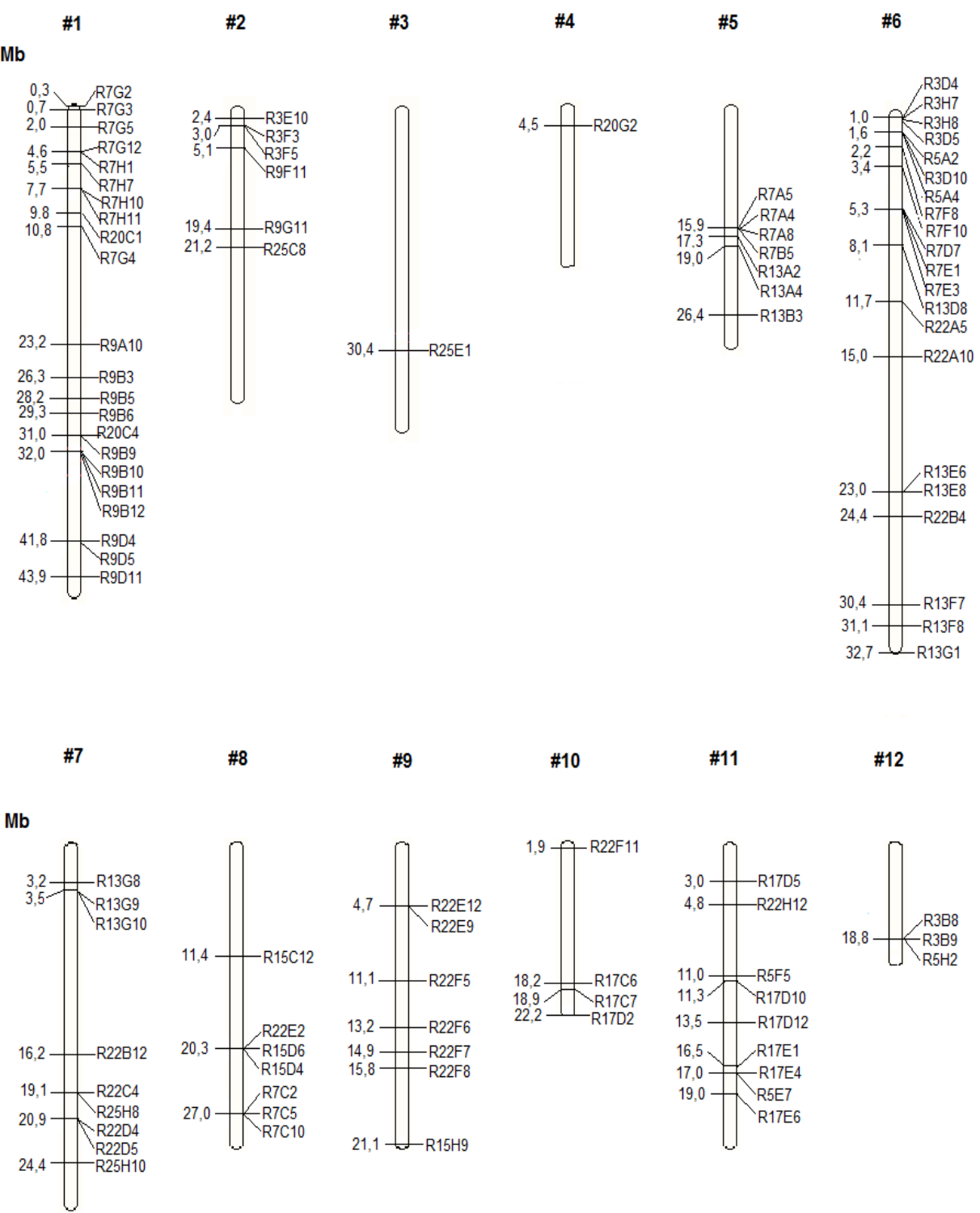

$\# 10$
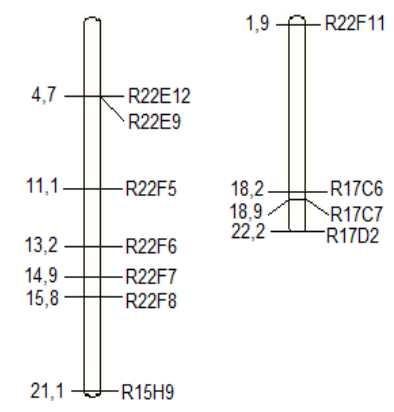

$\# 12$

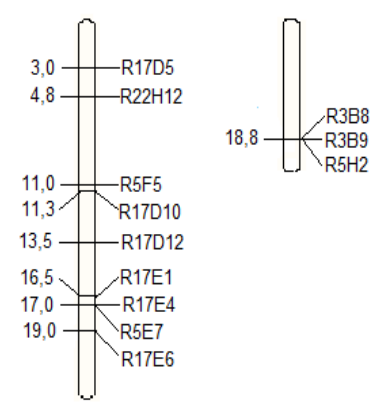

Note: Map distances between markers in mega bases (Mb). Numbers (\#1-\#12) represent the chromosomes. Marker names are on the right side and genetic distances are on the left side of the bars.

Figure 5. Physical map of P6DP and Chiem Tay landrace 
to $19.0 \mathrm{Mb}$, which is near the centromere, with the exception of the R13B3 marker, which is located at the $26.4 \mathrm{Mb}$ site. This may suggest that exchanges of these variations are difficult during the cross-over period.

Chromosomes 8 and 9 both showed seven polymorphic sites, but due to the difference in their lengths, the average distance among these variations was also different on each chromosome, $4.34 \mathrm{Mb}$ and $3.11 \mathrm{Mb}$, respectively. While the polymorphisms on chromosome 9 were evenly distributed, they tended to be located mainly at the site of 20.9 $\mathrm{Mb}$ and $24.4 \mathrm{Mb}$ on chromosome 8 .

Another chromosome that resulted in a relatively similar number of polymorphic markers was chromosome 2 with six variation sites, mostly located at the region from $2.4 \mathrm{Mb}$ to $5.1 \mathrm{Mb}$.

Only three polymorphic markers were observed on chromosome 12, all located around the position of $18.8 \mathrm{Mb}$. Chromosome 10 was observed with four polymorphic markers located far from the centromere, indicating potential for further breeding studies. There was only one marker on chromosomes 3 and 4 , which need to be supplemented with additional markers.

The development of physical map markers permits researchers to analyze genetic information of agronomical and physiological traits. Genetic maps in rice have been reported by many researchers, having polymorphic markers scattered quite evenly across the chromosomes or being condensed at particular regions have been shown. Harushima et al. (1998) stated that the markers, however, were not evenly distributed. The marker-dense regions where the nearest markers were less than $2 \mathrm{cM}$ apart composed only $33 \%$ of the total, and there were 60 gaps where the distance between adjacent markers was more than $5 \mathrm{cM}$. Muhammad et al. (2013) reported in their publication that the average interval distance between markers in their constructed linkage map between Pokkali and Shaheen Basmati was $16.2 \mathrm{cM}$ excepting several gaps of more than 30 $\mathrm{cM}$ were observed.

\section{Conclusions}

In summary, the present study found that there were wide variations in NUE values among the selected rice landraces cultivated in different regions of Northern Vietnam under different nitrogen conditions at different growth stages. The P6DB landrace consistently had the lowest NUE values at all the growth stages and in the $\mathrm{N}$ treatments. In contrast, the Chiem Tay landrace consistently showed the highest NUE values. Interestingly, the NUE did not gain higher values in accordance with increased increments of $\mathrm{N}$ applications in our experimental conditions. This information could be very useful for saving farming costs and the environment by reducing the application rate of $\mathrm{N}$ fertilizer. A physical map was constructed with 97 markers exhibiting good amplified polymorphic band patterns in the two cultivars that showed the lowest and highest NUE values, P6DB and Chiem Tay, respectively. These polymorphic markers were distributed along each of the 12 chromosomes and were either scattered quite evenly on a chromosome or tended to condense at particular regions. The marker map should provide a fruitful means for QTL mapping to identify QTLs/genes related to NUE as well as other genetic analyses toward the development of sustainable agriculture solutions.

\section{Acknowledgements}

We would like to thank ARES-CDD for financial support. We are also thankful to the Center of International Plant Research Vietnam and Japan at Vietnam National University of Agriculture for the use of their equipment and facilities.

\section{References}

Amano T., Zhu Q., Wang Y., Inoue N. and Tanaka H. (1993). Case studies on high yields of paddy rice in Jiangsu province, China. I. Characteristics of grain production. Japanese Journal of Crop Science. Vol 62. pp. 267-274.

Bing Z., Qi-Ming D., Qi-Jun Z., Jie-Qin L., Shao-Ping Y., Yong-Shu L., Yong P. and Ping L. (2006). Analysis of segregation distortion of molecular markers in F2 
population of rice. Acta Genetica Sinica. Vol 33 (5). pp. 449-457.

Broadbent F. E., de Datta S. K. and Laureles E. V. (1987). Measurement of nitrogen utilization efficiency in rice genotypes. Agronomy Journal. Vol 79. pp. 786-791.

Chandra R., Takeuchi H. and Hasegawa T. (2012). Hydrothermal pretreatment of rice straw biomass: a potential and promising method for enhanced methane production. Applied Energy. Vol 94. pp. 129-140.

Cuong P. V., Huong N. T., Hang D. T. T., Hanh T. T., Takuya A. and Toshihiro M. (2010). Nitrogen Use efficiency in $\mathrm{F}_{1}$ hybrid, Improved and Local Cultivars of rice (Oryza Sativa L.) during different cropping seasons. Journal of Science \& Development. Vol 8 (Eng. Iss. 1). pp. 59-68.

Davies D. B. and Sylvester-Bradley R. (1995). The contribution of fertilizer nitrogen to leachable nitrogen in the UK: a review. Journal of The Science of Food and Agriculture. Vol 68. pp. 399-406.

De Datta S. K. and Broadbent F. E. (1993). Development changes related to nitrogen-use efficiency in rice. Field Crop Research. Vol 34. pp. 47-56.

Dellaporta S. L., Wood J. and Hicks J. B. (1983). A plant DNA minipreparation: version II. Plant molecular biology reporter. Vol 1 (4). pp. 19-21.

Ferguson R. B., Hergert G. W., Schepers J. S., Gotway C. A., Cahoon J. E. and Peterson T. A. (2002). Sitespecific nitrogen management of irrigated maize, yield and soil residual nitrate effects. Soil Science Society of America Journal. Vol 66. pp. 544-553.

Guong V. T., Lap T. T., Hoa N. M., Castillo E. G., Padilla J. L. and Singh U. (1995). Nitrogen-use efficiency in direct-seeded rice in the Mekong River Delta: varietal and phosphorus response. Agricultural Information Management Standards. pp. 151-159.

Hamaoka N., Uchida Y., Tomita M., Kumagai E., Araki T. and Ueno O. (2013). Genetic variations in dry matter production, nitrogen uptake, and nitrogen use efficiency in the AA genome Oryzaspecies grown under different nitrogen conditions. Plant Production Science. Vol 16. pp. 107-116.

Hanh N. T. T., Cuong P. V. and Bertin P. (2014). The effect of nitrogen concentration on nitrogen use efficiency and related traits in cultivated rices (Oryza sativa L. subsp. indica and japonica and $\mathrm{O}$. glaberrima Steud.) in hydroponics. Euphytica. Vol 198. pp. 137-151.

Harushima Y., Yano M., Shomura A., Sato M., Shimano T., Kuboki Y., Yamamoto T., Lin S. Y., Antonio B. A., Parco A., Kajiya H., Huang N., Tamamoto K., Nagamura Y., Kurata N., Khush G. S. and Sakaki T. (1998). A high-density rice genetic map with 2,275 markers using a single $F_{2}$ population. Genetics. Vol 148. pp. 479-494.

Hashimoto M., Herai Y., Nagaoka T. and Kouno K. (2007). Nitrate leaching in granitic regosol as affected by $\mathrm{N}$ uptake and transpiration by corn. Soil Science and Plant Nutrition. Vol 53. pp. 300-309.

Hasegawa H. (2003). High-yielding rice cultivars perform best even at reduced nitrogen fertilizer rate. Crop Science. Vol 43. pp. 921-926.

Hawkesford M. J. (2011). An overview of nutrient use efficiency and strategies for crop improvement. Wiley, Sussex. pp. 5-19.

Hung N. N., Singh U., Xuan V.T., Buresh R. J., Padilla J. L., Lap T. T. and Nga T. T. (1995). Improving nitrogen-use efficiency of direct-seeded rice on alluvial soils of the Mekong River Delta. AGRIS. pp.138-149.

Inthapanya P., Sipaseuth, Sihavong P., Sihathep V., Chanphengsay M., Fukai S. and Basnayake J. (2000). Genotype differences in nutrient uptake and utilization for grain yield production of rainfed lowland rice under fertilized and non-fertilized conditions. Field Crops Research. Vol 65. pp. 57-68.

Ju J., Yamamoto Y., Wang Y., Shan Y., Dong G., Miyazaki A. and Yoshida T. (2009). Genotypic differences in dry matter accumulation, nitrogen use efficiency and harvest index in recombinant inbred lines of rice under hydroponic culture. Plant Production Science. Vol 12. pp. 208-216.

Kjeldahl J. (1883). New method for the determination of nitrogen in organic substances. Zeitschrift für analytische Chemie, Vol 22 (1). pp. 366-383.

Koutroubas S. D. and Ntanos D. A. (2003). Genotypic differences for grain yield and nitrogenutilization in Indica and Japonica rice under Mediterranean conditions. Field Crops Research. Vol 83. pp. 251260.

Mae T., Inaba A., Kaneta Y., Masaki S., Sasaki M., Aizawa M., Okawa S., Hasegawa S. and Makino A. (2006). A large-grain rice cultivar, Akita 63, exhibits high yields with high physiological N-use efficiency. Field Crops Research. Vol 97. pp. 227-237.

McCouch S. R., Kochert G., Yu Z. H., Wang Z. Y., Khush G. S., Coffman W. R. and Tanksley S. D. (1988). Molecular mapping of rice chromosomes. Theoretical and Applied Genetics. Vol 76 (6). pp. 815-829.

McCouch S. R., Teytelman L., Xu Y., Lobos K. B., Clare K., Walton M., Fu B., Maghirang R., Li Z., Xing Y., Zhang Q., Kono I., Yano M., Fjellstrom R., DeClerck G., Schneider D., Cartinhour S., Ware D. and Stein L. (2002). Development and mapping of 2240 new SSR markers for rice (Oryza sativa L.). DNA Research. Vol 9 (6). pp. 199-207.

Misselbrook T. H., Van der Weerden Y. J., Pain B. F., Jarvis S. C., Chambers B. J., Smith K. A., Phillips V. R. and Demmers T. G. M. (2000). Ammonia emission factors for UK agriculture. Atmospheric Environment. Vol 34. pp. 871-880.

Muhammad A. V., Fahrul Z. H., Takashige I., Azma A. S., Tariq M., Muhammad S. H. and Muhammad S. (2013). Construction of microsatellite linkage map 
and detection of segregation distortion in Indica rice (Oryza Sativa L.). Pakistan Journal of Botany. Vol 45 (6). pp. 2085-2092.

Namai S., Toriyama K. and Fukuta Y. (2009). Genetic variation in dry matter production and physiological nitrogen use efficiency in rice (Oryza sativa L.) varieties. Breeding Science. Vol 59. pp. 269-276.

Pathak R. R., Ahmed A., Lachab S. and Raghuram N. (2008). Molecular physiology of plant nitrogen use efficiency and biotechnological options for its enhancement. Current Science. Vol 94. pp. 13941401.

Peng S., Cassman K. G., Virmani S. S., Sheehy J. and Khush G. S. (1999) Yield potential trends of tropical rice since the release of IR8 and the challenge of increasing rice yield potential. Crop Science. Vol 39. pp. 1552-1559.

PRC - Plant Resources Center (2017). Plant germplasm information online. Retrieved on December 10, 2016 at http://csdl.prc.org.vn/Default.aspx.

Septiningsih E. M., Sanchez D. L., Singh N., Sendon P. M. D., Pamplona A. M., Heuer S. and Mackill D. J. (2012). Identifying novel QTLs for submergence tolerance in rice cultivars IR72 and Madabaru. Theoretical and Applied Genetics. Vol 124. pp. 867874.

Singh U., Ladha J. K., Castillo E. G., Punzalan G., TirolPadre A. and Duqueza M. (1998). Genotypic variation in nitrogen use efficiency in medium and long duration rice. Field Crops Research. Vol 58. pp. 35-53.

Socolow R. H. (1999). Nitrogen management and the future of food: lessons from the management of energy and carbon. Proceedings of the National Academy of Science of the United States of American. Vol 96. pp. 6001-6008.

Song W., Chen X. Y., Xu J. R. and Zhang Z. Y. (2003). Research progress in forest tree genetic linkage map construction and its future prospects. Yi Chuan. Vol 25 (6). pp. 749-756.

Tirol-Padre A., Ladha J. K., Singh U., Laureles E., Punzalan G. and Akita S. (1996). Grain yield performance of rice genotypes at suboptimal levels of soil $\mathrm{N}$ as affected by $\mathrm{N}$ uptake and utilization efficiency. Field Crops Research. Vol 46. pp. 127-143.

Ut T. T and Kei K. (2006). The impact of green revolution on rice production in Vietnam. The Developing Economies. Vol 2. pp. 167-189.

Vitousek P. M., Naylor R., Crews T., David M. B., Drinkwater L. E., Holland E., Johnes P. J., Katzenberger J., Martinelli L. A., Matson P. A., Nziguheba G., Ojima D., Palm C. A., Robertson G. P., Sanchez P. A., Townsend A. R. and Zhang F. S. (2009). Nutrient imbalances in agricultural development. Science. Vol 324. pp. 1519-1520.

Yang J., Peng S., Zhang Z., Wang Z., Visperas R. M. and Zhu Q. (2002). Grain and dry matter yields and portioning of assimilates in Japonica/Indica hybrid rice. Crop Science. Vol 42. pp. 766-772. 